\title{
TECHNO-ECONOMIC EVALUATION OF BROADBAND ACCESS ALTERNATIVES FOR IP SERVICES
}

This paper deals with a techno - economic evaluation of broadband upgrade strategy for IP services. This scenario is focused on the FTTcab/VDSL architecture with ATM versus Ethernet approaches. Target market is residential customers and small business customers in urban and dense urban areas. Installed First Cost (IFC) and Net present Value (NPV) as main techno - economic results are discussed regarding common assumptions. The results show that the choice of technology (Ethernet or ATM) has almost no effect on the cost level and profitability of the cases.

\section{Introduction}

VDSL, as one of many broadband alternatives for upgrading the existing access network offers up to $50 \mathrm{Mbps}$ to the customers. Advanced residential customers using the ADSL technology will expect faster applications and services in the near future. High capacity of VDSL require short copper loops and therefore fiber to a certain extent is needed in the access network. Two main technologies are candidates for new evolutions and IP-based services. The first is based on Gigabit Ethernet switching as technologies largely deployed in LAN is expected be cost effective. The second is based on Full Service Access Network (FSAN), whose main objective is accelerate optical penetration in the access network. It defined Broadband Passive optical Network (BPON), based on ATM as a low-cost fiber based access alternative.

In this paper TONIC and TITAN [2] tool for techno-economic evaluations of broadband access networks was used. Ten years deployment of both strategies is simulated on urban and dense urban areas with 65536 users and six classes of customers are defined depending on bit rates request or services demand.

Comparison scenario is realised for FTTCab/VDSL architecture with the two approaches (Ethernet versus ATM).

\section{Model case description}

Model in urban area is built on the Metropolitan Area Network (MAN) between Central Echange location and customer premises. Scenario depicted in figure 1 corresponds to the FTTCab/VDSL architecture, using either Gigabit Ethernet or ATM technology. Optical infrastructure is deployed between Central Exchange and Cabinet and copper cables are used from Cabinet to the customer locations. The urban area is modelled as an area of $8 \mathrm{~km}^{2}$ with an average copper loop of $300 \mathrm{~m}$ with the mean subscriber density
2048 subscribers $/ \mathrm{km}^{2}$ and the dense urban area is modelled as an area of $2.5 \mathrm{~km}^{2}$ with the subscriber density 6553 subscribers $/ \mathrm{km}^{2}$.

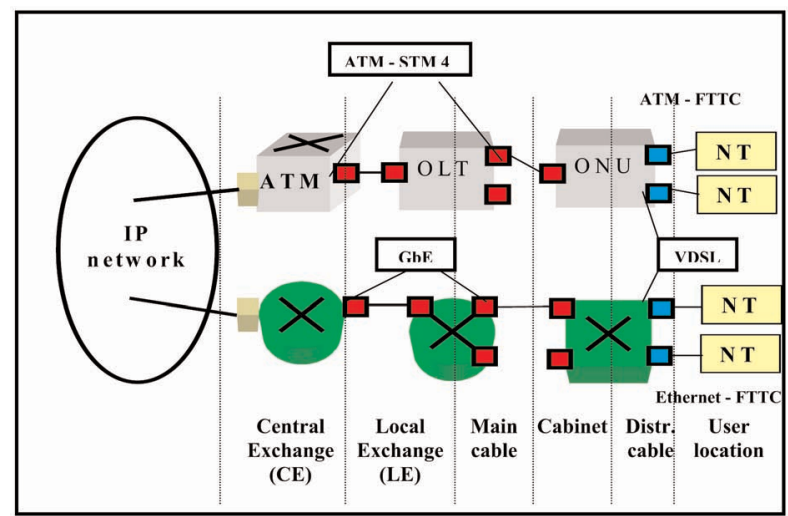

Fig. 1 FTTCab/VDSL architecture

In the Gigabit Ethernet approach, switches are deployed in Cabinet, Local Exchange (LE) and Central Exchange (CE). From $\mathrm{CE}$ to the Cabinet are the connections considered as Gigabit Ethernet connections and for the subscribers, as an Ethernet connec-

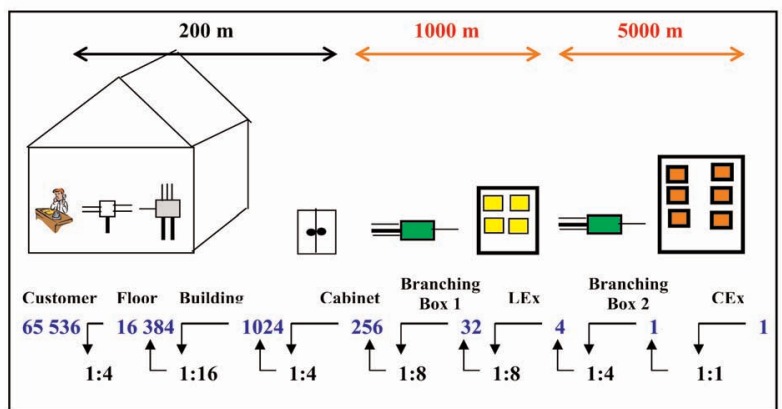

Fig. 2 Example of dense urban area

\footnotetext{
* Róbert Jankovský, Radoslav Odrobiňák

Department of Telecommunications, University of Žilina, Faculty of Electrical Engineering, Vel'ký diel, 01026 Žilina, Slovak Republic, E-mail: jankovsky@fel.utc.sk, odrobinak@fel.utc.sk
} 
tions over DSL CPE (Customer Premises Equipment) with e.g. one 10BaseT downlink interface [5].

In the second case, the OLT is connected to the backbone via an ATM switches and handles ONU through a point-to-point STM4 link. VDSL modem is installed in the customer locations.

We consider two types of areas: urban and dense urban areas for our scenario. The geometric model [6] can be used to calculate the cable and duct lengths. This model is layered by flexibility points (FPs) and link levels. In our case, each Central Office encompasses four Local Exchange.

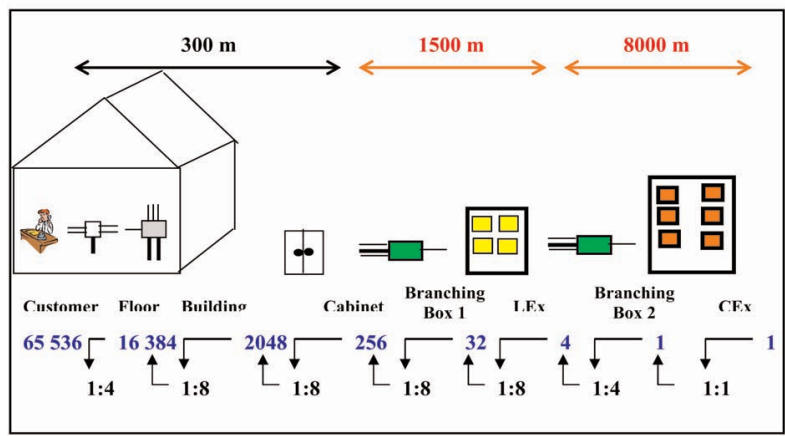

Fig. 3 Example of urban area

Now we must define the main parameters for both dense urban and urban areas. The dense urban area has shorter cable lengths than the urban area due to higher density of customers. So the number of the buildings is also different. The other parameter of infrastructure is for example duct availability, where we assumed the higher availability in the dense urban area than in the urban area.

\section{Service requests}

In this paper, users are divided into two main classes: residential and business customers. Type of service is dependent on a user profile. Besides, these two main classes can be divided into three subclasses. The range of services required by a business customer is even wider compared to residential customers (e.g. they require higher bit rates comparing to services dedicated to residential customers). Business subscribers often require symmetric bit rates while residential customers need high asymmetric bit traffic.

Broadband access forecast shows the number of incumbent operator subscribers in figure [7]. We assumed that total service
Residential customers

Table 2

\begin{tabular}{|c|c|c|}
\hline Service class & Applications & $\begin{array}{c}\text { Maximum bit rates } \\
\text { dowvstream (Mbps)- } \\
\text { asymmetric }\end{array}$ \\
\hline Class 1 & Fast Internet & 1 \\
\hline Class 2 & Fast Internet & 2 \\
\hline Class 3 & $\begin{array}{c}\text { Fast Internet, } \\
\text { One video channel }\end{array}$ \\
\hline
\end{tabular}

Business customers

Table 3

\begin{tabular}{|c|c|c|}
\hline Service class & Applications & $\begin{array}{c}\text { Maximum bit rates } \\
\text { dowvstream (Mbps)- } \\
\text { asymmetric }\end{array}$ \\
\hline Class 1 & Fast Internet, Intranet & 2 \\
\hline Class 2 & $\begin{array}{c}\text { Fast Internet, } \\
\text { Intranet, VoIP }\end{array}$ & 8 \\
\hline Class 3 & $\begin{array}{c}\text { Fast Internet, } \\
\text { Intranet, VoIP, } \\
\text { Data transmission }\end{array}$ & 24 \\
\hline
\end{tabular}

penetration is $55 \%$ and the market share of incumbent operator is $70 \%$. Then the total number customers of incumbent operator is $65536 * 50 \% * 70 \%=22938$. The monthly charge for asymmetric $1 \mathrm{Mbps}$ connection is set to 55 and for symmetric $2 \mathrm{Mbps}$ is set to 100_ in normalized values.

Provisioning represents $10 \%$, Network operations $10 \%$ and Sales and marketing $15 \%$ of total revenues. For all calculations in this paper, we assumed that Discount rate is set to $10 \%$ and Tax rate equals to zero. I used the cost database which contains current or estimated list price information for modelling of network costs [4]. The modelling process was realized in macro Excel language and in Visual Basic programming language. The numbers of incumbent operator customers are presented in figure 4 and 5 .

\section{Our scenario results}

We suppose 256 cabinet in each area with fiber-based technology up to the cabinet locations in our scenario. The connection between the cabinet and user locations is based on VDSL modem technology. Either it's Ethernet protocol based technology or ATM cell based in the case of FSAN. The difference between scenarious is in switching technology used.

Area description

Table 1

\begin{tabular}{|c|c|c|c|c|c|c|c|c|}
\hline Area & $\begin{array}{c}\text { Subscrib. } \\
/ \mathrm{km}^{2}\end{array}$ & $\begin{array}{c}\text { Cable length } \\
\text { CE-user }\end{array}$ & Surface & $\begin{array}{c}\text { Number of } \\
\text { buildings }\end{array}$ & $\begin{array}{c}\text { Subscrib. } \\
\text { per building }\end{array}$ & $\begin{array}{c}\text { Duct } \\
\text { availability } \\
\text { Lex-Cab }\end{array}$ & \% Bus. & $\%$ Res. \\
\hline Urban & 2048 & 6200 & 8 & 2048 & 32 & $60 \%$ & $60 \%$ & $60 \%$ \\
\hline Dense urban & 6553 & 9800 & 2.5 & 1024 & 64 & $90 \%$ & $40 \%$ & $40 \%$ \\
\hline
\end{tabular}






Fig. 4 Residential Service class

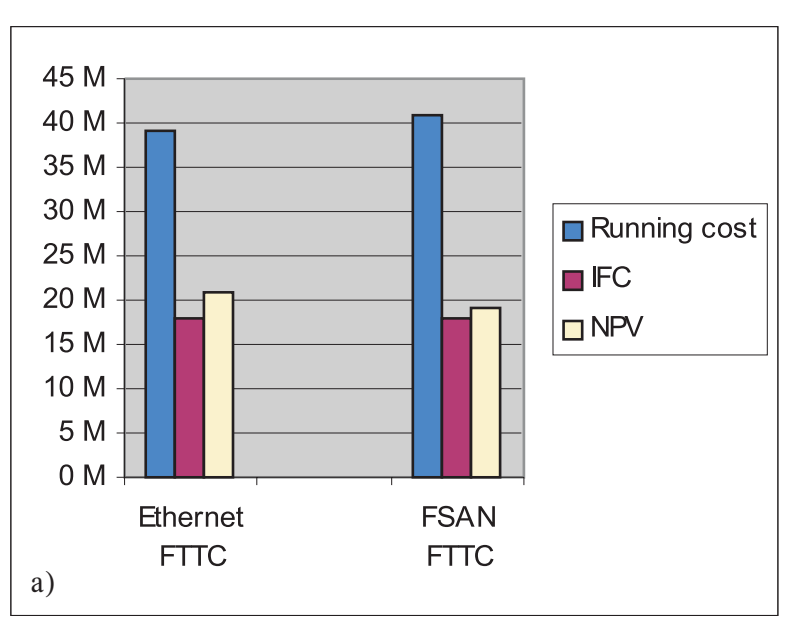

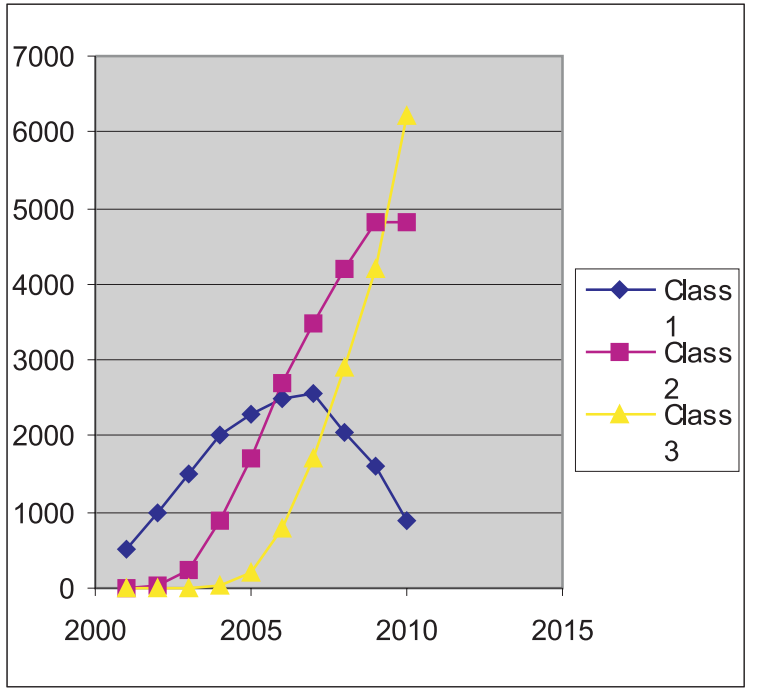

Fig. 5 Business Service class

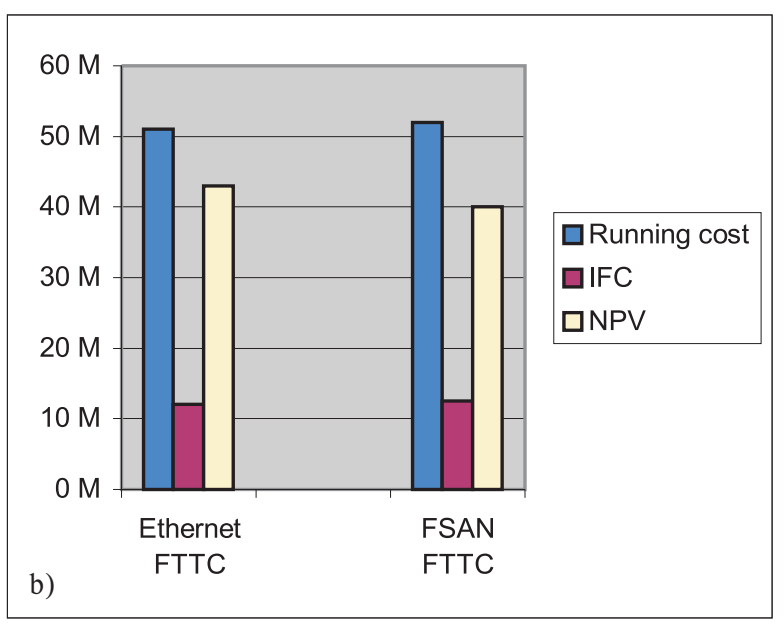

b)

Fig. 6 Costbreakdown for a) the urban area, b) the dense urban area

In figure 6 we can see only a slight difference for the same areas. But if we compare the areas, the NPV is higher in the dense urban than in the urban area. The investments are lower in the

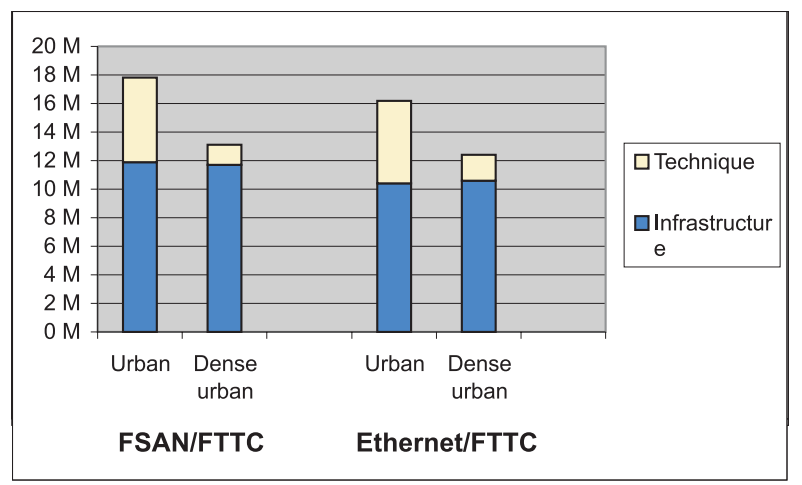

Fig. 7 IFC Breakdown dense urban area and revenues are higher because $60 \%$ of customers are business customers. Operation\&administration costs related to revenues are part of running costs and they are a bit higher in the dense urban area. On the other hand the NPV is twice higher in the dense urban area than in the urban area.

Figure 7 depicts IFC Breakdown into infrastructure and technique discounted investments. The difference in the same area is relatively small, up to $12 \%$. As we can expect investments in urban areas are higher than in dense urban areas due to infrastructure costs.

Figure 8 shows that the advantage of the Ethernet technology compared to FSAN/FTTC appears just in the beginning of the study period. The cash balance comparison in general is similar for both technologies. The Pay Back Period of the FSAN architecture can be reached after 6.2 years versus 6.0 years for Ethernet in urban areas and 4.6 years for FSAN versus 4.1 years for Ethernet in dense urban areas. 


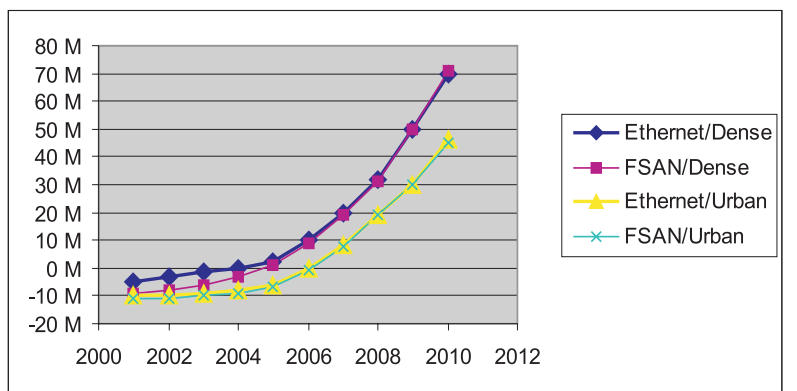

Fig. 8. Cash balance comparison

\section{Component cost versus time}

The cost evolution of every component in a special cost database is described by the following parameters:

- Reference year

- Price at a given reference year

- Volume class, which gives the cost of the component as a function of time with three parameters: $n_{r}(0), \Delta T$, and $\gamma$.

- $n_{r}(0)$, which is the accumulated production volume by $t=0$

- $\Delta T$, which is the time it takes for the accumulated production volume to increase from $10 \%$ to $90 \%$ of the total accumulated production volume

- $\gamma$, which describes the asymmetry of the applied logistic curve

- Learning curve class, which gives the cost of the component as a function of produced volume with one parameter, K: optimistic or pessimistic

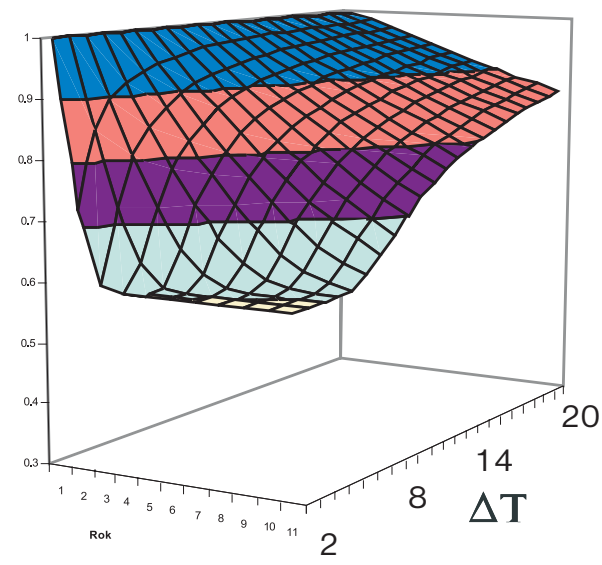

Fig. 9 The impact $\Delta T$ on the normalised price, if $n_{r}(0)=0,001$

The final expression for price versus time in general is:

$$
C(t)=C(0)^{*}\left[n_{r}(0)^{-1 *}\left(1+e^{\left\{\ln \left[n_{r}(0)^{-1}-1\right]-\left[\frac{2 * \ln 9}{\Delta T}\right] *_{t}\right\}}\right)^{-1}\right]^{\log _{2}{ }^{*} \gamma}
$$

Five parameters are the input to the formula:

$C(0)$ - price in the reference year 0

$n_{r}(0)$ - relative accumulated volume in year 0

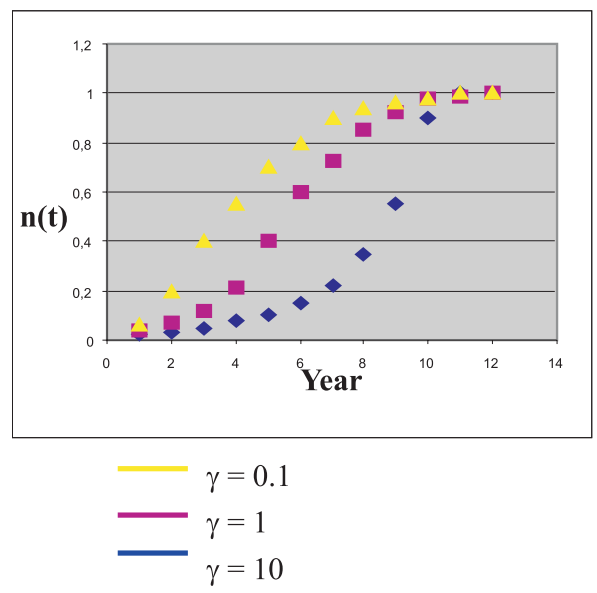

Fig. 10 The impact $\Delta T$ on the normalised price, keeping $\Delta T=5$ years

$\Delta T$ - time for accumulated volume to grow from $10 \%$ to $90 \%$ $K$ - learning curve coefficient $\gamma$ - asymmetry of the logistic curve

\section{Conclusion}

This paper presents the results obtained from simulation of techno - economic evolution broadband alternatives. These simulations are based on experiences obtained in TITAN and TONIC project and they are realized in the programming language $\mathrm{C}++$ and in Excel tools.

For two areas (dense urban and urban), scenarios focused on the FTTCab/VDSL architecture with two approaches (Ethernet versus ATM) are realized for comparison. With the given assumptions FTTC solutions for urban and dense urban areas result in a positive NPV (net present value) with a payback period between approximately five and six years. The positive NPV is mainly driven by the existing infrastructure in terms of ducting systems, the housing infrastructure and the short total connection distance to the customers.

The most important variables are tariffs, the network operation costs, the access equipment costs and customer penetration or their density. The point-to-point Ethernet FTTC architectures seem to be a plausible solution as a first migration step after ADSL for both dense urban a urban areas. The results for FTTC show that choice of technology (Ethernet or ATM) has almost no effect on the cost level and profitability of the cases.

The figures for investment breakdown show just a small difference between different technologies. The differences have nothing to do with the protocol architecture, but rather with interface granularity and fiber consumption.

Figure 11 depicts the possible target architectures for broadband technologies in light of their integration to Next-Generation Networks (NGN). 


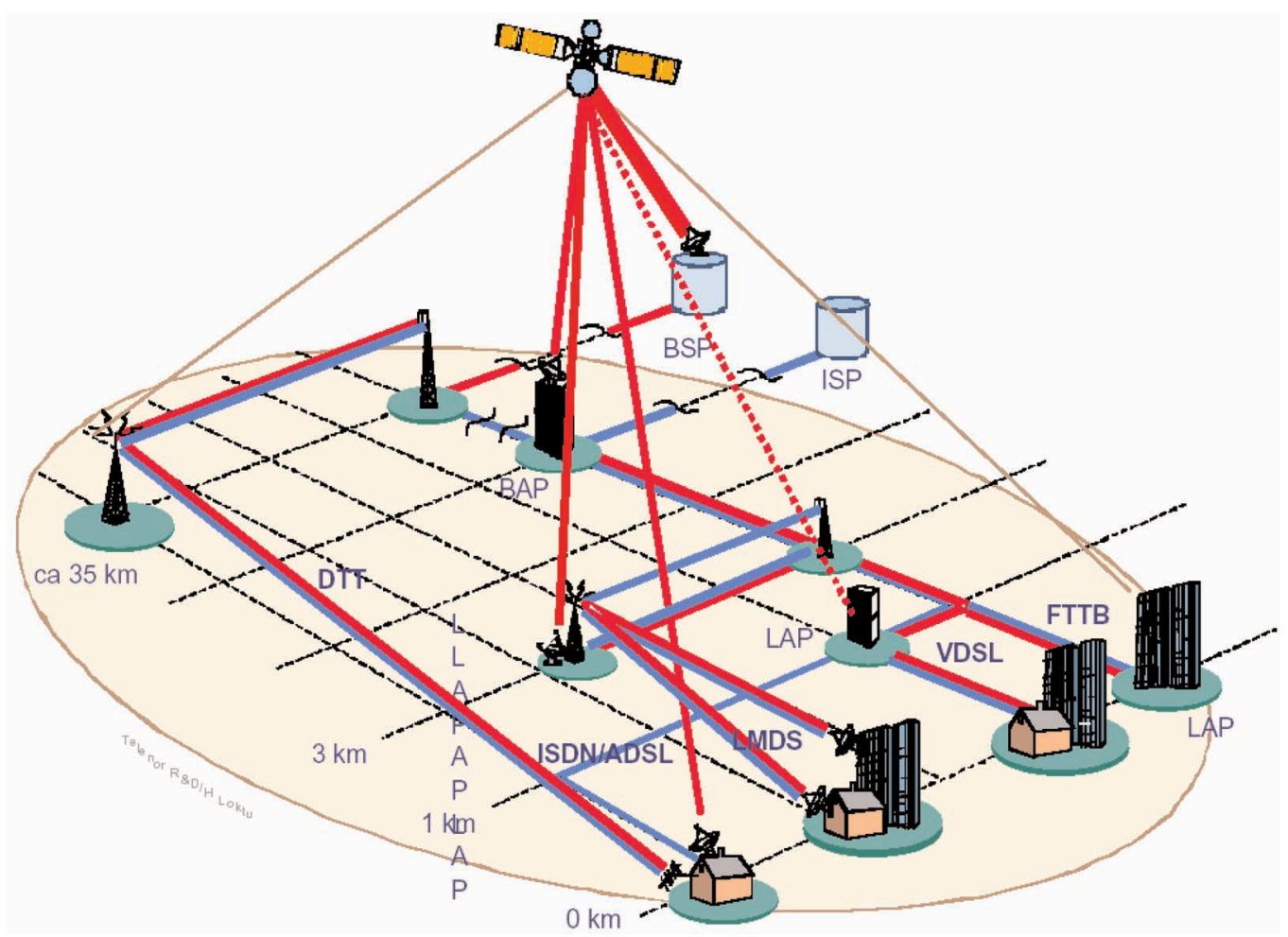

Fig. 11 Target architecture for broadband technologies

\section{References}

[1] MONATH, T., ELNERGAARD, N., CADRO, PH., DEVOLDERE, P.: "Devirable 4: First results on broadband network solutions for new IP services offered in the fixed networks", IST-2000-25172 TONIC.

[2] IMS, L.A. (editor): "Broadband access networks - Introduction strategies and techno-economic analysis", Chapman-Hall, January, 1998.

[3] STORDHALL, K., RAND, L.: Long Term Forecast for broadband Demand, Telektronik, vol. 95, no. 2/3, 1999.

[4] Deliverable 8, “Market Models for IP Services", IST-2000-25172 TONIC, May 2002.

[5] MONATH, T. et al.: "Economics of Ethernet Based Access networks for Broadband IP Services", XIV Int'I. Symp. Services and Local Access, Seoul, Korea, Apr. 14-18, 2002.

[6] JANKOVSKÝ, R.: "Návrh geometrických modelov pre prístupové siete”, medzinárodná konferencia, ELEKTRO, 2004.

[7] Stordhall, K., Ims, L. A., Moe, M.: "Broadband Market - The Driver for Network Evolution", Proc. Networks 2000, Toronto, Canada, Sept. 10-16, 2000. 